\title{
Gynaecological Near-Miss from Meleney's Gangrene Post- Abdominal Myomectomy: A Case Report
}

\section{Babatunde Olaniyi ROSIJI', Omagbeitse Henry ABIYERE ${ }^{2}$, Babatunde Ajayi OLOFINBIYI ${ }^{3}$, Olalekan Oladipupo ROSIJI', Blessing Oluwatosin OLANREWAJU ${ }^{1}$ and Olakunle John AYELOJA ${ }^{1}$}

\author{
${ }^{1}$ Department of Obstetrics and Gynaecology, State specialist Hospital, Ikole Ekiti, Nigeria \\ ${ }^{2}$ Department of Surgery, Federal Teaching Hospital, Ido-Ekiti, Nigeria \\ ${ }^{3}$ Department of Obstetrics and Gynaecology, Ekiti State University, Ado-Ekiti, Nigeria \\ ${ }^{4}$ Department of Obstetrics and Gynaecology, Federal Teaching Hospital, Ido-Ekiti, Nigeria
}

*Corresponding author: Dr. Rosiji Babatunde Olaniyi, Department of Obstetrics and Gynaecology, State Specialist Hospital, Ikole-Ekiti PMB 5011, Ikole-Ekiti, Nigeria, Tel: +2348-034-376-969; +2340-805-828-7173

\begin{abstract}
Necrotizing fasciitis is a severe, rare, potentially lethal soft tissue infection that develops in the scrotum and perineum, the abdominal wall or the extremities [1]. It progresses rapidly and septic shock may ensue [1,2]. When the anterior abdominal wall is involved it is referred to as Meleney's gangrene [3]. It is seen as a serious complication of surgery which evolves rapidly and could carry a high mortality rate of $30-50 \%$, approaching up to $90 \%$ in diabetic patients [3-6]. It is a synergistic infection involving microaerophilic non-haemolytic streptococci and aerobic haemolytic staphylococci but may also involve various other aerobes and anaerobes $[2,7,8]$. It requires a high index of suspicion for early diagnosis and treatment. Unfortunately, the early symptoms and signs of this condition are non-specific and the diagnosis can be easily missed $[9,10]$. We report the development of cardiovascular collapse followed by development of Meleney's gangrene in a 38-year-old P3+ [2] woman after an uneventful abdominal myomectomy. We wish to share the difficulty encountered in making the diagnosis from the non-specific symptoms and management protocol adopted to ensure full recovery of the patient especially in a low resource setting.
\end{abstract}

\section{Keywords}

Meleney, Gangrene, Necrotizing, Fasciitis, Cardiovascular, Collapse

\section{Introduction}

Abdominal myomectomy is a commonly performed gynaecological procedure for varying indications especially in symptomatic women with future desire for fer- tility. It is a fairly safe procedure especially with haemostatic steps such as use of cervico-isthmic catheters to reduce blood loss during surgery [11]. With meticulous obliteration of dead spaces created by enucleation of leiomyomas, post-operative infective and febrile morbidities are grossly reduced.

Necrotizing fasciits of the anterior abdominal wall is a very rare condition especially following gynaecological procedures [12]. It is described classically as a synergistic infection involving microaerophilic non-haemolytic streptococci and aerobic haemolytic staphylococci but may also involve various other aerobes and anaerobes $[2,7,8]$ beta haemolytic streptococcus acting in synergy with certain anaerobic organisms [1,2]. Predisposing factors for this condition include immune-compromise, diabetes mellitus and low socio-economic status among others [2].

\section{Case Report}

We report the case of a 38-year-old P3+ [2] woman who had abdominal myomectomy on account of symptomatic uterine fibroids (menorrhagia and pain) of 3 years duration. She was not a known diabetic or hypertensive. The uterus was enlarged up to 26 weeks and her body mass index was $22.3 \mathrm{~kg} / \mathrm{m}^{2}$. Her pre-operative haemogram and kidney function tests were within normal limits and fasting blood sugar was normal.

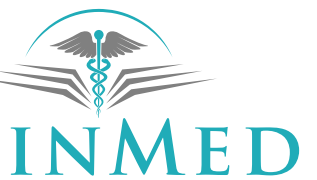

INTERNATIONAL LIBRARY

Citation: ROSIJI BO, ABIYERE OH, OLOFINBIYI BA, ROSIJI OO, OLANREWAJU BO, et al. (2020) Gynaecological Near-Miss from Meleney's Gangrene Post-Abdominal Myomectomy: A Case Report. Obstet Gynecol Cases Rev 7:176. doi.org/10.23937/2377-9004/1410176

Accepted: October 01, 2020: Published: October 03, 2020

Copyright: (C) 2020 ROSIJI BO, et al. This is an open-access article distributed under the terms of the Creative Commons Attribution License, which permits unrestricted use, distribution, and reproduction in any medium, provided the original author and source are credited. 
She had abdominal myomectomy following laid down unit protocols and thirty (30) pieces of leiomyomas of varying sizes were removed and submitted for histopathological assessment. They demonstrated varying degrees of degenerative changes. Layered closure of the anterior abdominal wall was done using delayed absorbable sutures (polygycolic acid). Of particular note was a thickened sub-cutaneous layer measuring approximately $6 \mathrm{~cm}$ in thickness. The intra-operative blood loss was $180 \mathrm{mls}$. She had a smooth immediate post-operative course with a post-operative packed cell volume of $30 \%$. She was discharged on the $4^{\text {th }}$ post-operative day but decided to wait till the $6^{\text {th }}$ post-operative day to sort-out post-discharge formalities.

On the $6^{\text {th }}$ post-operative day while in a seated position, she developed a sudden onset of tiredness and profuse sweating. While attempting to return to a supine position she fell and lost consciousness. Patient was noticed to be in cardiovascular collapse as the pulse rate was 118 beats per minute while the blood pressure was $50 / 30 \mathrm{mmHg}$ and she was febrile to touch. Random blood sugar was $5.7 \mathrm{mmol} / \mathrm{L}$. She was immediately resuscitated with intravenous infusion of normal saline and intranasal oxygen. Within 30 minutes of resuscitation, patient regained consciousness and the blood pressure normalized to $100 / 70 \mathrm{mmHg}$. Further examination of the abdomen revealed a well healed pfannensteil scar and a minimal area of blister adjoining the edge of the zinc-oxide-coated plaster measuring approximately $3 \times$ $4 \mathrm{~cm}$. Her temperature was $38.7^{\circ} \mathrm{C}$.

Abdominal ultrasound was done which excluded any intra-abdominal collection but there was minimal stasis of peristaltic motions on visualization of bowel loops. Repeat packed cell volume was $30 \%$ and $\mathrm{E} / \mathrm{U} / \mathrm{Cr}$ was essentially normal. Blood samples were obtained for blood culture and serial abdominal girth measurement did not reveal any progressive abdominal distension and there was no area of undue tenderness.

She was recommenced on 'nil per oris' due to a reduced perception of bowel sounds and a presumed diagnosis of suspected paralytic ileus with ? gram negative septicaemia. The wound care was continued with methylated spirit and gentian violet while special attention was given to the blistered area which was presumed to be a reaction to the zinc oxide coated plaster. Intravenous antibiotics were recommenced and patient monitoring was continued.

She appeared to be making good clinical progress until she attempted to sit out of bed on the $7^{\text {th }}$ post-operative day when she experienced another episode of fainting attack with deterioration of her vital signs. Blood pressure was $60 / 30 \mathrm{mmHg}$, pulse rate was 117 beats per minute and the temperature was $37.9^{\circ} \mathrm{C}$. Resuscitation produced an instant normalization of her vital signs and patient was nursed in supine position. Her blood pressure became 100/70 mmHg while her pulse rate was 101 beats per minute. Some induration was noticed on the anterior abdominal wall superior to the pfannensteil incision which was intact and healing well. A presumed diagnosis of anterior abdominal wall cellulitis was made and the antibiotic regimen was continued.

On the $8^{\text {th }}$ post-operative day a discolouration was noticed around the blister site which was now ruptured and discharging sero-sanguinous fluid. A swab sample was obtained for microscopy culture and sensitivity while intravenous gentamycin was added to her antibiotic regimen.

On the $9^{\text {th }}$ post-operative day the discolouration noted around the former blister site was noticed to be spreading upwards and laterally on both sides and the patient developed superficial tenderness in both flanks and her temperature became $39^{\circ} \mathrm{C}$. The microscopy culture and sensitivity returned on the $10^{\text {th }}$ post-operative day and returned growth of Pseudomonas aeruginosa and Proteus mirabilis which were maximally sensitive to augmentin, cefixime, cefuroxime and ceftriaxone. Her antibiotic was changed to include intravenous ceftriaxone $1 \mathrm{~g} 12$ hourly. An assessment of necrotizing fasciitis (Meleney's gangrene) was made and the need for wound debridement was explained to the patient.

A consult was sent to the general surgical team and the patient was scheduled for wound debridement under general anaesthesia. Intraoperative findings revealed area of extensive gangrene involving a portion of skin above the pfannesnteil incision and extending to the subcutaneous tissue immediately beneath the skin and extending laterally to both lumbar regions and stopping just short of the umbilicus superiorly (Figure 1). All gangrenous tissue was excised and additional chemical debridement was done using $2 \%$ hydrogen peroxide solution while the subcutaneous layer was packed with EUSOL soaked gauze on either side. The patient continued on daily wound dressing, vital signs normalized and the wound granulated progressively (Figure 2 and Figure 3) till a secondary closure was done on the $60^{\text {th }}$ post-operative day (Figure 4).

She was eventually discharged from the ward on the $70^{\text {th }}$ post-operative day (Figure 5) and followed up in the gynaecological clinic. Her visits to the gynaecological clinics have been uneventful.

\section{Discussion}

Necrotizing fasciitis is a rare condition especially the anterior abdominal wall variety which is commonly referred to as Meleney's gangrene [1,3]. Meleney's gangrene is known to be a rapidly progressing necrotizing fasciitis caused by bacteria acting in a synergistic manner to effect maximum tissue destruction within a very short period of time [3]. It complicates anterior abdominal wall surgeries but in very rare instances minor 


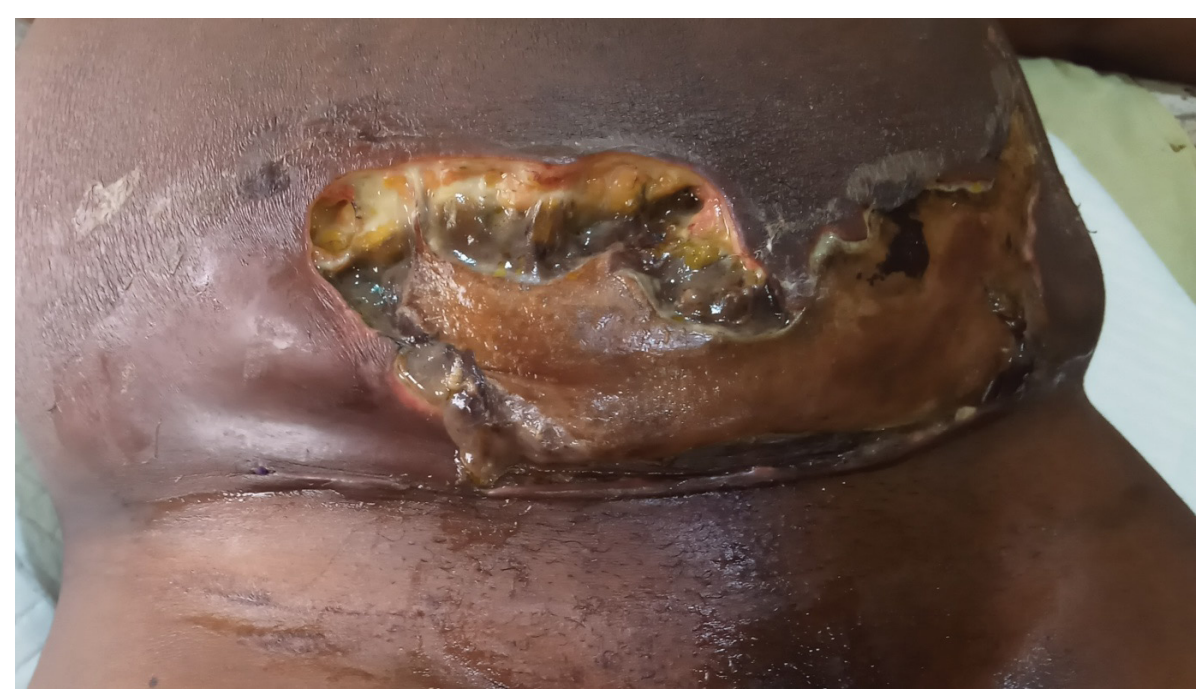

Figure 1: Wound just before debridement.

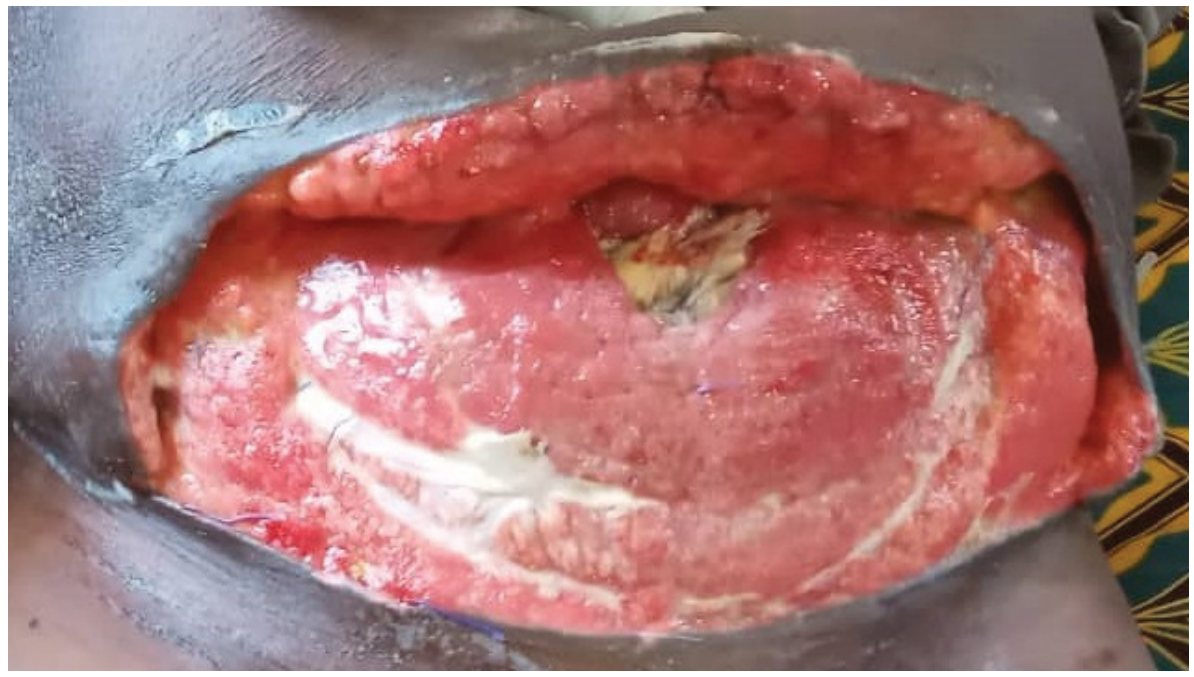

Figure 2: Wound 8 Days after debridement and Wound dressing.

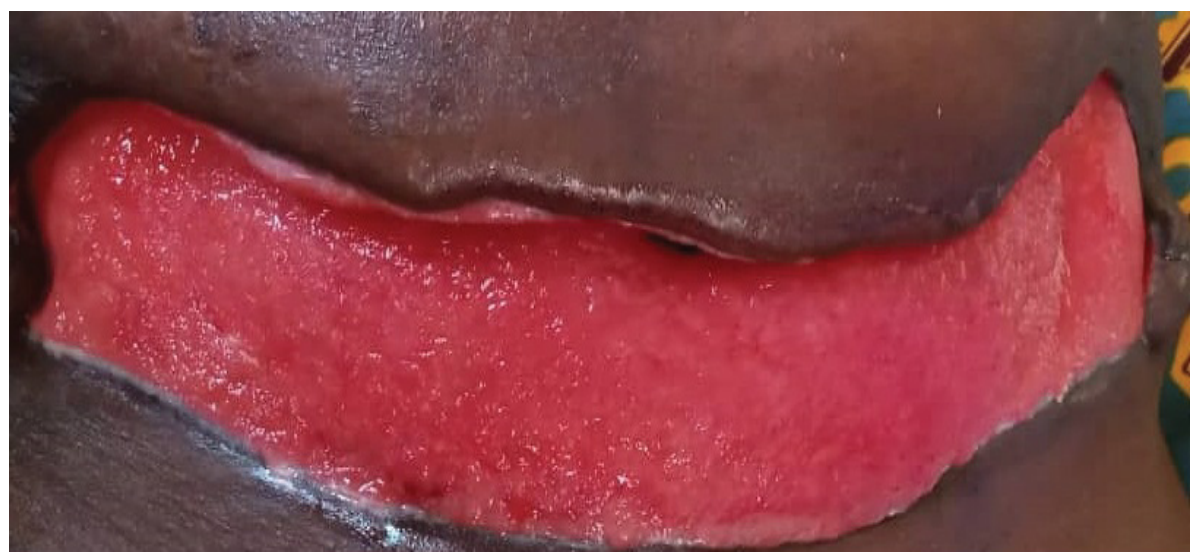

Figure 3: Wound 24 Days after debridement and Wound dressing.

injuries such as abrasions or scratches to the skin of the abdomen might be the portal of entry $[5,6,8]$.

The organisms responsible for this condition belong to a vast array of aerobes and anaerobes acting synergistically to result in an infectious morbidity which has a mortality of $30-50 \%$ and even up to $90 \%$ especially in individuals with compromised immunity and diabetics [3-6].

The patient above is not a known diabetic and there is no clinical history suggestive of immune-compromise. She however had a thickened abdominal fatty layer which caught attention during surgery. Despite a nor- 


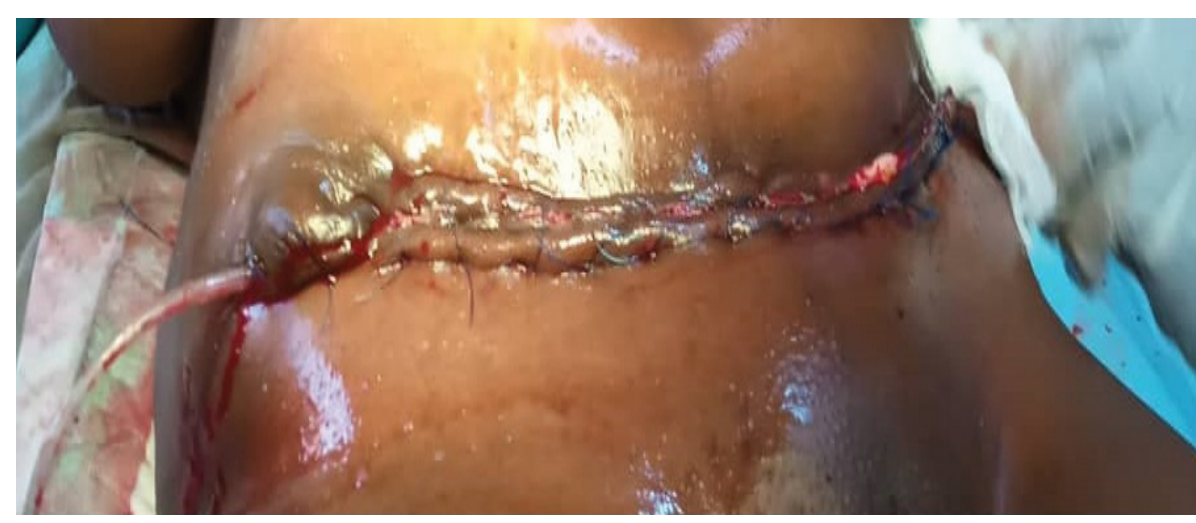

Figure 4: Secondary wound closure 45 Days after debridement.

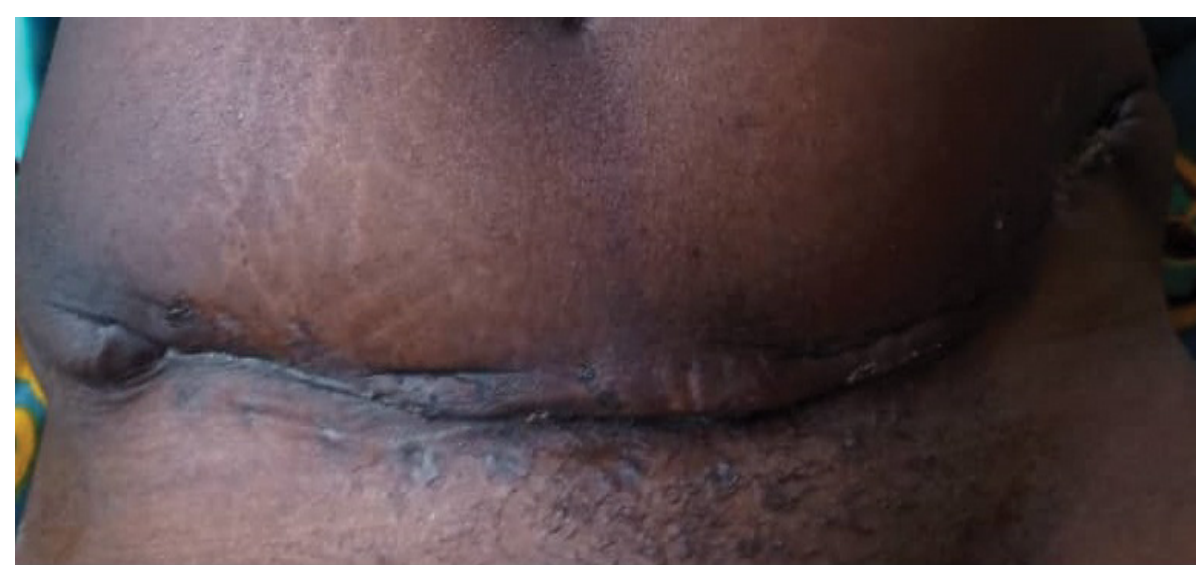

Figure 5: Wound at discharge.

mal body mass index, this truncal obesity was the only identifiable risk factor in this patient [13].

The immediate post-operative period in this patient was uneventful and the first sign of danger was a sudden onset of fainting attack post-discharge which was suspected to be from gram negative endotoxic shock. This cardiovascular collapse could be the earliest warning sign in some patients [14], and if missed could result into delay in treatment and mortality. The skin changes on the patient's abdominal wall were not specific except for a bullous reaction superior to the incision line which was thought to be due to zinc oxide toxicity and it was associated with non-specific induration of surrounding skin which was thought to be a straight forward cellulitis. However a progressive worsening of the bullous reaction ranging from rupture to discolouration of surrounding skin and apparent gangrene of the skin and subcutaneous tissues developed rapidly. This leads credence to the fact that a high index of suspicion is needed for the diagnosis of necrotizing fasciitis as the early symptoms and skin changes are non-specific and delay in definitive management could be life-threatening [15].

Parenteral antibiotics and extensive surgical debridement is the documented management of choice $[16,17]$ and in this case the persistent fever observed in the patient crashed within a few hours of debridement and recommencement of parenteral antibiotics. Surgi- cal debridement was combined with chemical debridement using $2 \%$ hydrogen peroxide. This was followed up with daily dressing using gauze packs soaked in eusol which was later changed to pure honey dressing.

The patient was provided with psychological support and placed on high protein and high-calory diet in addition to blood transfusion to optimize her haematocrit above $30 \%$. These steps resulted in progressive improvement of her wound as evidenced by progressive granulation and reduction of wound size.

The wound was dressed daily for a total of 44 days and the patient had secondary wound closure on post-operative day 45 . The wound eventually healed completely around the $60^{\text {th }}$ post-operative day and the patient was eventually discharged. The progression of the disease is as shown in the attached images.

Early diagnosis, institution of parenteral antibiotics and extensive debridement with subsequent wound dressing are proven measures for optimal care and reduction of mortality in necrotizing fasciitis $[18,19]$.

\section{Conclusion}

Meleney's gangrene is a fatal complication of surgery but early diagnosis, parenteral antibiotics and extensive wound debridement are important steps in the reduction of mortality. Sudden onset of shock in a post-operative patient that was hitherto stable after exclusion of 
haemorrhagic complication of surgery should strongly raise a suspicion for an evolving necrotizing fasciitis.

\section{Funding}

There was no financial support from any source for the conduct of this study. This research did not receive any specific grant from funding agencies in the public, commercial, or not-for-profit sectors.

\section{Declaration of Interest}

There are no interests to declare.

\section{Disclosure} ted.

All authors have approved the final article as submit-

\section{Author Contribution}

Conceptualization: Babatunde Olaniyi ROSIJI, Omagbeitse Henry ABIYERE

Drafting the article: Babatunde Olaniyi ROSIJI, Babatunde Ajayi OLOFINBIYI

Critical revision of the article: Olalekan Oladipupo ROSIJI, Blessing Oluwatosin OLANREWAJU, Olakunle John AYELOJA

Final approval of version to be submitted: All authors

\section{Informed Consent}

A written consent has been obtained from the patient in this report to use the pictures taken during clinical care. All steps have been taken to ensure that patient's confidentiality is maintained.

\section{References}

1. Misiakos EP, Bagias G, Patapis P, Sotiropoulos D, Kanavidis $P$, et al. (2014) Current concepts in the management of necrotizing fasciitis. Front Surg 1: 36.

2. Roje Z, Roje Z, Matic D, Librenjak D, Dokuzovic S, et al. (2011) Neccrotizing fasciitis: Literature review of contemporary strategies for diagnosing and management with three case reports: Torso, abdominanl wall, upper and lower limbs. Word J Emerg Surg 23: 46.

3. Meleney FL (1931) Bacterial synergism in disease processes: With a confirmation of the synergistic bacterial aetiology of a certain type of progressive gangrene of the abdominal wall. Ann Surg 94: 961-981.

4. Meleney FL, Brewer GE (1926) Progressive gangrenous infection of the skin and subcutaneous tissues, following operation for acute perforative appendicitis: A study in symbiosis. Ann Surg 84: 438-450.

5. Meleney FL, Shambugh P, Millen RS (1950) Systemic bacitracin in the treatment of progressive bacterial synergistic gangrene. Ann Surg 131: 129-144.

6. David AB, Robinson KP, Hedd R (1982) Meleney's progressive synergistic bacterial gangrene due to subcutaneous end-ileostomy perforation, with delayed plastic reconstruction. J R Soc Med 75: 749-750.

7. Wallance $S$ (1935) Progressive post operative gangrene of the skin. BJS 22: 642-656.

8. Wong C, Wanfg Y (2005) The diagnosis of necrotizing fasciitis. Curr Opin Infect Dis 18: 101-106.

9. Lille ST, Sato TT, Engrav LH, Foy H, Jurkovich GJ (1996) Necrotizing soft tissue infections: Obstacles in diagnosis. $J$ Am Coll Surg 182: 7-11.

10. Anaya DA, Dellinger EP (2007) Necrotizing soft tissue infection: Diagnosis and management. Clin Infect Dis 22: 705-710.

11. Ikechebelu JI, Ezeama CO, Obiechina NJ (2010) The use of tourniquet to reduce blood loss at myomectomy. Niger $\mathrm{J}$ Clin Pract 13: 154-158.

12. Huljev D, Kucisec-Tepes N (2005) Necrotizing fasciitis of the abdominal wall as a post-surgical complication: A case report. Wounds 17: 169-177.

13. Francis KR, Lamaute HR, Davis JM, Pizzi WF (1993) Implications of risk factors in necrotizing fasciitis. Am Surg 59: 304-308.

14. Stevens DL, Tanner MH, Winship J (1989) Severe group A streptococcal infections associated with a toxic shock-like syndrome and scarlet fever toxin. N Engl J Med 321: 1-7.

15. Wang YS, Wong CH, Tay YK (2007) Staging of necrotizing fasciitis based on the evolving cutaneous features. Int $\mathrm{J}$ Dermatol 46: 1036-1041.

16. Majeski JA, Alexander JW (1983) Early diagnosis, nutrition support and immediate extensive debridement improve surgical necrotizing fasciitis. Am J Surg 145: 785-787.

17. Dworkin M, Westercamp M, Park L, McIntyre A (2009) The epidemiology of necrotizing fasciitis including factors associated with death and amputation. Epidemiol Infect 137: 1609-1614.

18. Huang KF, Hung MH, Lin YS, LU CL, Liu C, et al. (2011) Independent predictors of mortality for necrotizing fasciits: A retrospective analysis of a single institution. J Trauma 71: 467-473.

19. Kalaivani V, Hiremath BV, Indumathi VA (2013) Necrotizing soft tissue infection-risk factors for mortality. J Clin Diagn Res 7: 1662-1665. 